\title{
Histological profile and age at diagnosis of breast and ovarian tumors: A register-based study in Espirito Santo, Brazil
}

\author{
ELDAMÁRIA DE VARGAS WOLFGRAMM ${ }^{1}$, CAMILA FÁTIMA BIANCARDI GAVIOLI ${ }^{1}$, \\ MAYARA LEMOS ENTRINGER ${ }^{1}$, LYVIA NEVES REBELLO ALVES ${ }^{1}$, ELAINE STUR ${ }^{1}$, \\ ALLAN KARDEC DE CASTRO NETO ${ }^{2}$, LUCIENE LAGE DA MOTTA ${ }^{3}$, \\ FAUSTO EDMUNDO LIMA PEREIRA ${ }^{1}$ and IURI DRUMOND LOURO ${ }^{1}$
}

\author{
${ }^{1}$ Center of Molecular and Human Genetics, Department of Biology, Federal University of Espirito Santo, \\ Vitória 29043-900; ${ }^{2}$ Pathology Laboratory, Santa Rita de Cássia Hospital, Vitória 29043-260; ${ }^{3}$ Pathology Laboratory, \\ Santa Casa de Misericórdia de Vitoria Hospital, Vitória 29018-180, Espirito Santo, Brazil
}

Received September 18, 2012; Accepted October 29, 2012

DOI: $10.3892 / \mathrm{mco} .2012 .38$

\begin{abstract}
Breast and ovarian cancers are important public health problems in Brazil. However, in various locations in the Brazilian territory these types of cancer remain poorly characterized. Therefore, this study aimed to compare data collected from the Pathology Services of two Oncology Reference Hospitals in Espirito Santo state (Brazil) with the data in previous Brazilian studies. Histological type frequency and age at diagnosis of breast and ovarian tumors between 2001-2004 and 2009-2010 were analyzed. Tumor size, histological grade, lymph node status, hormone receptor status [estrogen (ER) and progesterone receptors (PR)] as well as HER2 and Ki-67 marker status were obtained for the cases of infiltrating ductal carcinomas of the breast during the period 2009-2010. Categorical variables were described by their absolute and/or relative frequencies, while quantitative variables were expressed as the mean \pm standard deviation and median, using $95 \%$ confidence intervals. Chi-square tests were performed to examine whether or not the studied variables differed by age at the time of diagnosis. Malignant breast tumors $(1,758)$ and 119 malignant ovarian tumors were examined. Mean ages for malignant breast and ovarian tumors were 53.59 and 52.98 years, respectively. An increased tumor frequency in the age group of $\leq 35$ years was observed for other malignant tumors of the breast during the period of 2009-2010, compared to 2001-2004. When considering only infiltrating ductal carcinomas with immunohistochemistry records available, there were $82.1 \%$ (133 cases)
\end{abstract}

Correspondence to: Dr Iuri Drumond Louro, Center of Molecular and Human Genetics, Department of Biology, Federal University of Espirito Santo, Marechal Campos Avenue 1468, Maruípe, Vitória 29043-900, Espirito Santo, Brazil

E-mail: iurilouro@yahoo.com

Key words: breast and ovarian tumors, Brazil, epidemiology, histological data of $\mathrm{ER}^{+} / \mathrm{PR}^{+}$tumors, $1.9 \%$ (3 cases) of $\mathrm{ER}^{-} / \mathrm{PR}^{-} / \mathrm{HER} 23^{+}$and $16.04 \%$ (26 cases) of ER//PR/HER2- tumors. The findings of this study demonstrated detailed information concerning breast and ovarian tumor behavior in the Espirito Santo state (Brazil), allowing for a precise comparison with other populations (Brazilian or international), which may be helpful in the planning of prevention and treatment strategies.

\section{Introduction}

Breast cancer is the most common malignant tumor among women, accounting for one in four types of cancer diagnosed in women worldwide. Over 1.1 million women are diagnosed with this disease each year and incidence rates are still on the increase in several countries (1). In Brazil, breast cancer is an important public health problem, due to the high incidence, morbidity and mortality rates (1), which are unequally distributed throughout the country, with the South and Southeast constituting the regions with the highest reported breast cancer rates (2).

An incidence ratio of 52 breast cancer cases per 100,000 women is estimated in Brazil for 2012 (52,680 cases/year). The Southeast region has the highest incidence ratio of 69 new cases/100,000 women, while the South region has a similar incidence ratio of 65 cases/100,000 women (3). The Espirito Santo state, located in the Southeast region, has a breast cancer rate of 49.42/100,000 women for the year 2012, while the State's capital, Vitoria, a rate of 71.28/100,000 women (3). Recently, the Brazilian media reported significant increases in breast cancer incidence in women $<35$ years of age, generating public distress and concern (4).

Ovarian cancer is the fourth most frequent type of cancer in women. According to American studies, the risk ratio of developing ovarian cancer in a woman's life-time is estimated to be $1 / 70$. The incidence increases with age, reaching its peak in the eighth decade (5).

During the period 2001-2005, the age-adjusted mortality rate due to ovarian cancer was 8.8/100,000 women per year in the United States (6). In Europe, various mortality rates 
have been reported. In Germany and the majority of western European countries, ovarian cancer incidence is almost $12 / 100,000$ women, while it is lower in Southern Europe (9.3/100,000 women in Italy) and France (9.7/100,000 women). Total mortality due to ovarian cancer in Poland is $12.5 / 100,000$ women, while the highest rate is reported in Northern Europe (13.9/100,000 women in Norway and $13.4 / 100,000$ women in the UK) (7).

Ovarian cancer is also a public health problem in Brazil. Although not the most common type of female cancer, it constitutes a major cause of mortality among gynecological cancers (8). According to the estimations 5,530 Brazilian women were diagnosed with ovarian cancer in 2008, with 2,982 women succumbing to the disease (3.0/100,000 women) (9).

According to data obtained from the Brazilian National Cancer Institute (Instituto Nacional de Câncer, INCA), an incidence ratio of 6.17 cases per 100,000 women is estimated in Brazil for 2012 (6,190 cases/year). The Southeast region has demonstrated an estimated risk of 7 new cases per 100,000 women and the Espirito Santo state has demonstrated a previously reported rate of 5.92/100,000 women (3).

In an attempt to provide current data and a more comprehensive analysis of Brazilian breast and ovarian cancer epidemiology, this study aimed to examine histological type frequencies and age at the time of diagnosis for breast and ovarian tumors in Espirito Santo state, Brazil. Moreover, tumor size, histological grade, lymph node and hormone receptor status [estrogen (ER) and progesterone receptors (PR)] as well as HER2 and Ki-67 marker status for infiltrating ductal carcinomas, the most frequent malignant tumor of the breast, were investigated. Information was obtained after reviewing data from the Pathology Services of two Oncology Reference Hospitals in Espirito Santo state [the Santa Rita de Cássia and the Santa Casa de Misericórdia de Vitória Hospitals (Vitoria, Brazil)].

\section{Materials and methods}

Data collection and categorization. Female breast and ovarian, malignant and benign tumor data accumulated during the period 2001-2004 in the Pathology Service of the Santa Casa de Misericórdia de Vitória Hospital as well as for 2001-2004 and 2009-2010 in the Pathology Service of the Santa Rita de Cássia Hospital were analyzed. Information concerning histological type and age at the time of diagnosis were obtained for the breast and ovarian tumors. Tumor size, histological grade, lymph node and hormone receptor status (ER/PR) as well as HER2 and Ki-67 marker status were obtained for infiltrating ductal carcinomas of the breast during 2009-2010 in the Santa Rita de Cássia Hospital.

Breast tumors were categorized into infiltrating ductal carcinomas, carcinomas, other malignant tumors, fibroadenomas and other benign tumors. Ovarian tumors were categorized into serous cystadenocarcinomas, mucinous cystadenocarcinomas, carcinomas, other malignant tumors, serous cystadenomas, mucinous cystadenomas, teratomas and other benign tumors. Immunohistochemical analysis of ER, PR and HER2 gene products was used to categorize tumors as luminal $\left(\mathrm{ER}^{+} / \mathrm{PR}^{+}\right)$, HER2 $\left(\mathrm{ER}^{-} / \mathrm{PR}^{-} / \mathrm{HER} 23^{+}\right)$and triple-negative (ER-/PR $/$ HER2 $^{-}$).
Patients that sought medical assistance at the studied Hospitals are representative of the entire population of Espirito Santo state with regard to breast and ovarian cancer, since the two hospitals are Cancer Reference Hospitals for the residents of the surrounding urban and rural regions.

Statistical analysis. The SPSS version 17.0 and GraphPad Prism 5 were used for data handling and statistical analyses. For the descriptive analysis, categorical variables were described by their absolute and/or relative frequencies, and quantitative variables were expressed as the mean \pm standard deviation (SD) and median, using 95\% confidence intervals (CI). Chi-square tests were performed to examine whether or not the studied variables differed among the age groups $\leq 35$, $\geq 36$ to $\leq 55$ and $\geq 56$ years. This study was approved by the Ethics Committee of the Federal University of Espirito Santo (Vitoria, Brazil; protocol no. 02/09), including the informed consent waiver, and was performed in compliance with the Ethical Standards of the Declaration of Helsinki in 1975.

\section{Results}

Distribution of breast tumors by histological type and their correlation to age. There were 1,758 malignant, 2,570 benign and 21 phyllodes tumors of the breast during the period analyzed. Infiltrating ductal carcinoma was the most frequent malignant tumor $(81.74 \%)$, responsible for $33.04 \%$ (1,437 cases) of the breast tumor cases (Table I).

The mean age at diagnosis for malignant breast tumors was 53.59 years (SD, 13.29; 95\% CI, 52.96-54.21), with a median age of 52 years (range 14-101), respectively, accounting for $15.1 \%$ of the cases (266 cases; 95\% CI, 13.43-16.77) <40 and $2.1 \%$ of the cases (37 cases; 95\% CI, 1.43-2.77) $<30$ years. When considering only cases $\leq 35$ years (126 cases), a mean age of 31.38 (SD, 3.66; 95\% CI, 30.83-32.12) and a median age of 32 years were observed, accounting for $70.63 \%$ of the cases (89 cases; 95\% CI, 62.68-78.58) $>30$ years. The distribution of breast tumors by histological type and their correlation to age are described in Table I.

Frequency of breast tumors. Breast tumor frequency in the age groups $\leq 35,36-55$ and $\geq 56$ years is shown in Fig. 1 . A statistically significant higher frequency of infiltrating ductal carcinomas was observed in the 36-55 $(\mathrm{P}<0.0001)$ and $\geq 56$ year $(\mathrm{P}<0.0001)$ age groups during 2009-2010, compared to 2001-2004 (Fig. 1B and C). Additionally, a higher frequency was observed for other malignant tumors in the age groups analyzed $(\mathrm{P}=0.0172, \mathrm{P}=0.0011$ and $\mathrm{P}<0.0001$ for the groups $\leq 35$, $36-55$ and $\geq 56$ years, respectively) (Fig. 1A-C). No additional significant frequency differences were observed for carcinomas of the breast in the age groups during the time periods analyzed.

Fibroadenomas developed less frequently in the age groups $\leq 35$ and $36-55$ years ( $\mathrm{P}<0.0001$ for both groups) during 2009-2010, when compared to 2001-2004 (Fig. 1A and B). Similarly, other benign tumors of the breast developed less frequently in the age group $\leq 35$ years $(\mathrm{P}<0.0001)$ during 2009-2010 compared to 2001-2004 (Fig. 1A).

Frequency and histological characteristics of infiltrating ductal carcinomas. The histological characteristics of the 
Table I. Distribution of breast and ovarian tumors by histological type and their correlation to age.

\begin{tabular}{|c|c|c|c|c|c|c|c|}
\hline \multirow[b]{2}{*}{ Lesion site } & \multirow[b]{2}{*}{ Histological type } & \multirow[b]{2}{*}{ No. } & \multicolumn{5}{|c|}{ Age (years) } \\
\hline & & & Mean & $\mathrm{SD}$ & Median & Minimum & Maximum \\
\hline \multirow[t]{10}{*}{ Breast } & Infiltrating ductal carcinoma & 1,437 & 53.42 & 13.265 & 51.00 & 19 & 101 \\
\hline & Lobular & 59 & 54.64 & 11.011 & 52.00 & 37 & 87 \\
\hline & Tubular/cribiform & 54 & 51.25 & 10.804 & 51.00 & 31 & 79 \\
\hline & Mucinous/colloid & 28 & 57.79 & 15.337 & 56.00 & 37 & 92 \\
\hline & Papillary & 44 & 60.30 & 18.918 & 62.50 & 14 & 89 \\
\hline & Other malignant tumors & 136 & 52.39 & 12.850 & 52.50 & 14 & 82 \\
\hline & Fibroadenoma & 996 & 31.95 & 13.068 & 30.00 & 8 & 84 \\
\hline & Other benign tumors & 1,574 & 44.33 & 13.600 & 45.00 & 5 & 88 \\
\hline & Phyllodes & 21 & 45.00 & 13.791 & 49.00 & 12 & 63 \\
\hline & Total & 4,349 & 44.93 & 15.996 & 45 & 5 & 101 \\
\hline \multirow[t]{9}{*}{ Ovary } & Serous cystadenocarcinoma & 21 & 50.95 & 14.733 & 49.00 & 30 & 85 \\
\hline & Mucinous cystadenocarcinoma & 5 & 60.00 & 8.426 & 56.00 & 53 & 71 \\
\hline & Carcinoma & 9 & 56.89 & 15.358 & 51.00 & 42 & 82 \\
\hline & Other malignant tumors & 84 & 53.25 & 16.721 & 57.50 & 16 & 89 \\
\hline & Serous cystadenoma & 183 & 44.87 & 14.845 & 44.00 & 13 & 87 \\
\hline & Mucinous cystadenoma & 56 & 45.48 & 14.266 & 46.00 & 17 & 85 \\
\hline & Teratoma & 124 & 37.02 & 14.969 & 36.00 & 3 & 77 \\
\hline & Other benign tumors & 1,015 & 42.08 & 11.618 & 43.00 & 3 & 97 \\
\hline & Total & 1,497 & 43.40 & 13.181 & 44 & 3 & 97 \\
\hline
\end{tabular}

SD, standard deviation.

infiltrating ductal carcinomas registered in the Santa Rita de Cássia Hospital during 2009-2010 are described in Table II. Undifferentiated tumors (grade III) comprised 9.4\% (10 cases) in the age group $\leq 35$ years, $49.1 \%$ (52 cases) in the age group $36-55$ years and $41.5 \%$ ( 44 cases) in the age group $\geq 56$ years.

With regard to hormone receptors, $38.9 \%$ (21 cases) were $\mathrm{ER}^{+}, 6.7 \%$ (9 cases) were $\mathrm{ER}^{-}, 37 \%$ (20 cases) were $\mathrm{PR}^{+}$and $18.5 \%$ (10 cases) were $\mathrm{PR}^{-}$in the age group $\leq 40$ years, while $38.7 \%$ (86 cases) were $\mathrm{ER}^{+}, 11.3 \%$ (25 cases) were ER-, 33.8\% ( 75 cases) were $\mathrm{PR}^{+}$and $15.3 \%$ (34 cases) were $\mathrm{PR}^{-}$in the age group $\geq 50$ years. For the age group $\leq 35$ years, $2.60 \%$ ( 5 cases) were $\mathrm{ER}^{-} / \mathrm{PR}^{-}$and $4.69 \%$ (9 cases) were $\mathrm{ER}^{+} / \mathrm{PR}^{+}$.

Regarding HER 2 expression, $80 \%$ (8 cases) of the HER2 $3^{+}$ cases (overexpression cases) were diagnosed in the age group 36-55 years. Concerning the Ki-67 marker, $50 \%$ (93 cases) of the positive cases were diagnosed in the age group 36-55 years.

We observed $82.1 \%$ (133 cases) of luminal tumors, $1.9 \%$ ( 3 cases) of HER2 tumors and $16.04 \%$ (26 cases) of triple-negative tumors. A statistically significant trend towards triple-negative tumors was observed in the age group $\leq 35$ years $(\mathrm{P}=0.0360)$.

Distribution of ovarian tumors by histological type and their correlation to age. Concerning ovarian tumors, 119 malignant and 1,378 benign tumors (including cysts) were examined (Table I). The mean age for women with ovarian cancer was 52.98 years (SD, 15.634; 95\% CI, 50.14-55.82), with a median age of 53 years, ranging from 16 to 89 years, respectively, accounting for $58.8 \%$ of the cases (70 cases; $95 \% \mathrm{CI}, 49.96-67.64)$ of $\geq 50$ years. With regard to the benign tumors of the ovary, the mean age was 42.14 years (SD, 12.666; $95 \% \mathrm{CI}, 41.46-42.81$ ), with a median age of 43 years, ranging from 3 to 97 years, respectively.

Frequency of ovarian tumors. Among ovarian tumors, mucinous cystadenocarcinomas had the highest mean age at diagnosis (60 years; SD, 8.426), while teratomas the lowest (37.02 years; SD, 14.969) (Table I). A higher frequency was observed for other malignant tumors of the ovary and serous cystadenomas in the age group $\geq 56$ years $(\mathrm{P}=0.0151$ and $\mathrm{P}=0.0255$, respectively) during the period $2009-2010$ compared to 2001-2004 (Fig. 1F).

\section{Discussion}

This study investigated the histological type frequency and the age at the time of diagnosis of breast and ovarian tumors in the Espirito Santo state, Brazil. Samples were obtained from two Oncology Reference Hospitals. Breast and ovarian cancer histological types were similar for the two Hospitals. However, the Santa Rita de Cássia Hospital had a significantly larger number of cancer cases, justifying the collection of data for 2009-2010 only from this Hospital.

Data regarding tumor size, histological grade, lymph node status and hormone receptor status as well as HER2 and Ki-67 marker status for infiltrating ductal carcinomas 
A

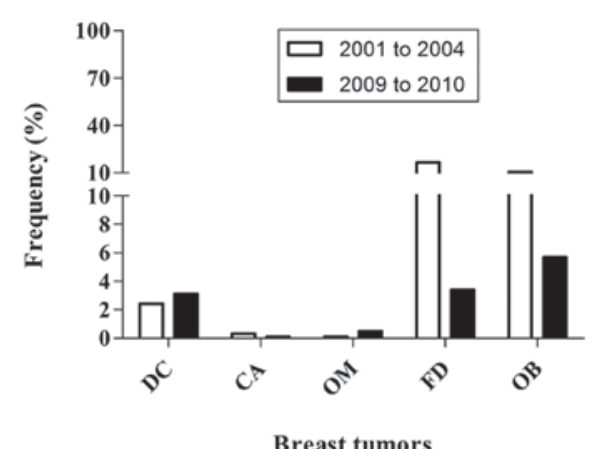

B

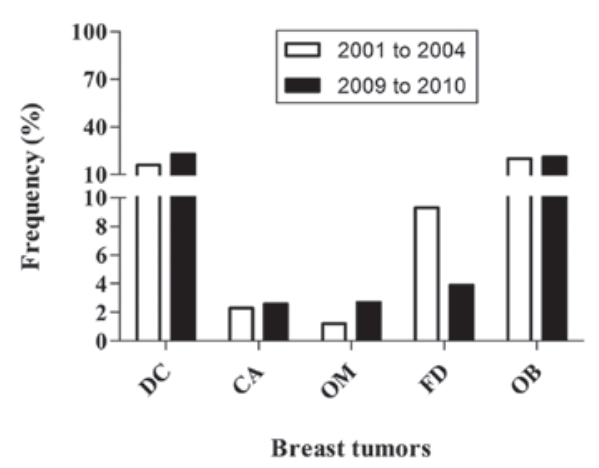

C

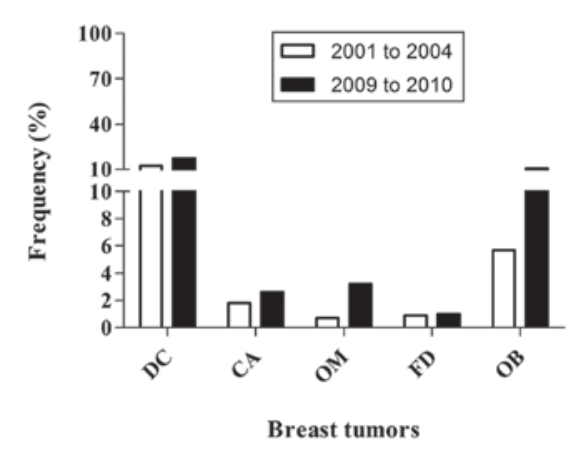

D

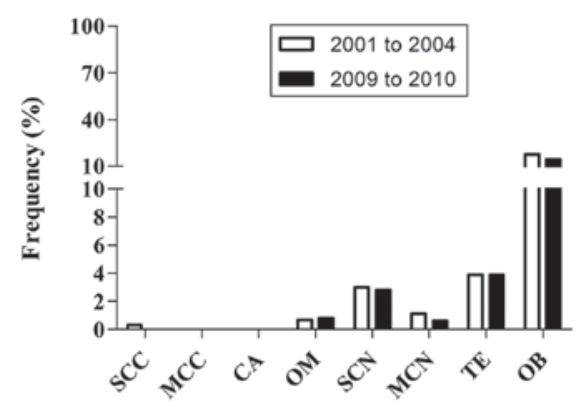

Ovary tumors

$\mathbf{E}$

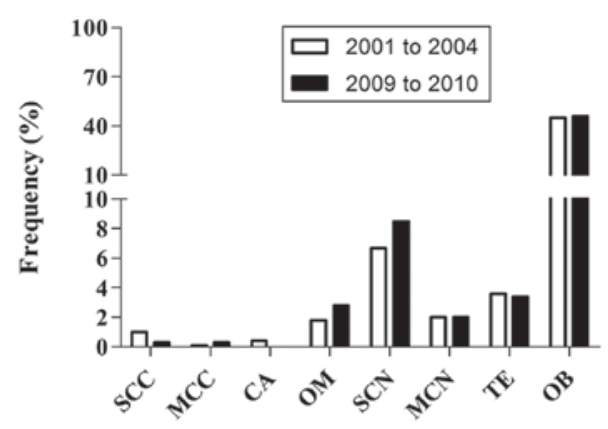

Ovary tumors

$\mathbf{F}$

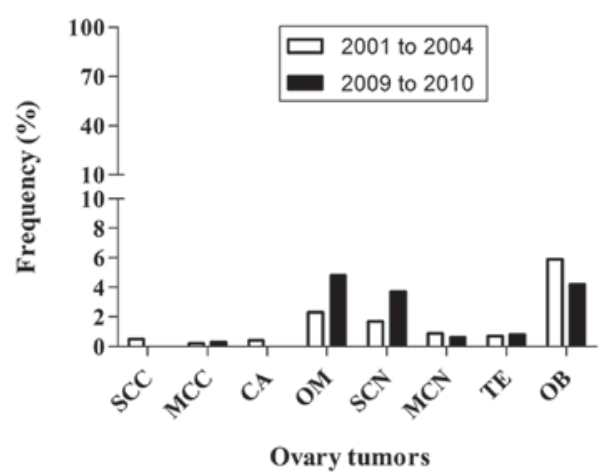

Figure 1. Frequency of breast and ovarian tumors registered in the Pathology Services. (A and D) Age group $\leq 35$ years, (B and E) age group $36-55$ years, (C and F) age group $\geq 56$ years. (A-C) Breast tumors, (D-F) ovarian tumors. DC, infiltrating ductal carcinoma; CA, other carcinomas; OM, other malignancies; FD, fibroadenoma; OB, other benign tumors; SCC, serous cystadenocarcinoma; MCC, mucinous cystadenocarcinoma; SCN, serous cystadenoma; MCN, mucinous cystadenoma; TE, teratoma.

were available only for the time period 2009-2010, due to the lack of information for previous years and for other types of malignant tumors.

The mean age at diagnosis for malignant breast tumors in our study was similar to that of another study analyzing samples from Florianópolis (Santa Catarina, Brazil) (10). By contrast, our results demonstrated a lower mean and median age at diagnosis when compared with cases from Juiz de Fora (Minas Gerais, Brazil) (11). The age group of $\leq 35$ years also presented results similar those of the study conducted with samples obtained from Florianópolis (12). Frequencies observed in the age groups $\leq 30$ and $\leq 40$ years were different from the frequencies described in the literature, reporting $\sim 0.6 \%$ of cancer cases in women $<30$ years and $6.5 \%$ in women $<40$ years (13).

The fact that the cancer rates were higher during 2009-2010 when compared to 2001-2004 was consistent with a Brazilian study conducted examining samples from Goiânia (Goiás, Brazil) (4). According to this study (4), a significant increase in breast cancer incidence was observed in the age groups (20-39, 40-59 and $\geq 60$ years) over the years analyzed (1988-2003). This increase in breast cancer rates may be due to an improvement in cancer screening programs resulting from a wider clinical application of mammography. 
Table II. Histological characteristics of infiltrating ductal carcinomas during 2009-2010.

\begin{tabular}{|c|c|}
\hline Histological characteristics & $\mathrm{n}(\%, 95 \% \mathrm{CI})$ \\
\hline Histological grade & 317 \\
\hline I & $14(4.4,2.1-6.7)$ \\
\hline II & $197(62.1,56.8-67.4)$ \\
\hline III & $106(33.4,28.2-38.6)$ \\
\hline Tumor size, right breast & 51 \\
\hline $\mathrm{T} 1$ & $37(72.5,60.2-84.8)$ \\
\hline $\mathrm{T} 2$ & $12(23.5,11.9-35.1)$ \\
\hline $\mathrm{T} 3$ & $2(3.9,0.0-9.2)$ \\
\hline Tumor size, left breast & 61 \\
\hline $\mathrm{T} 1$ & $40(65.6,53.7-77.5)$ \\
\hline $\mathrm{T} 2$ & $17(27.9,16.6-39.2)$ \\
\hline $\mathrm{T} 3$ & $4(6.6,0.4-12.8)$ \\
\hline Tumor size, without location & 154 \\
\hline $\mathrm{T} 1$ & $107(69.5,62.2-76.8)$ \\
\hline $\mathrm{T} 2$ & $42(27.3,20.3-34.3)$ \\
\hline $\mathrm{T} 3$ & $5(3.2,0.4-5.9)$ \\
\hline Lymph node status & 379 \\
\hline Positive & $104(27.4,22.9-31.9)$ \\
\hline Negative & $275(72.6,68.1-77.1)$ \\
\hline ER status & 195 \\
\hline Positive & $152(77.9,72.1-83.7)$ \\
\hline Negative & $43(22.1,16.3-27.9)$ \\
\hline PR status & 192 \\
\hline Positive & $139(72.4,66.1-76.7)$ \\
\hline Negative & $53(27.6,21.3-33.9)$ \\
\hline HER2 status & 35 \\
\hline $1^{+}$ & $14(40,23.8-56.2)$ \\
\hline $2^{+}$ & $11(31.4,16.0-46.8)$ \\
\hline $3^{+}$ & $10(28.6,13.6-43.6)$ \\
\hline Ki-67 status & 187 \\
\hline Positive & $186(99.5,98.5-100.5)$ \\
\hline Negative & $1(0.5,0.0-1.5)$ \\
\hline
\end{tabular}

CI, confidence interval; ER, estrogen receptor; PR, progesterone receptor.

Infiltrating ductal carcinomas demonstrated no statistically significant differences in histological grade, lymph node involvement and tumor size in the age groups. These results are consistent with a study using samples from Ribeirão Preto (São Paulo, Brazil) (13), where no differences in histopathological tumor features were observed in the age groups $\leq 40$, $40-50$ and $\geq 50$ years at diagnosis. By contrast, a study analyzing samples of invasive ductal breast cancer in Belém (Pará, Brazil) (14) provided different results. That study reported $59.1 \%$ T4 tumors (26 cases), $93.2 \%$ of locally advanced disease at diagnosis (41 cases; T3 and T4 tumors) and 93.2\% of clinically affected lymph nodes (41 cases) (14), while the present study observed $4.14 \%$ T3 tumors (11 cases; 95\% CI, 1.75-6.53) and $27.4 \%$ lymph node-positive tumors (104 cases; 95\% CI, 22.91-31.89). The higher rates observed in the study conducted using samples from Belém (14) are likely to be due to the fact that the patients had advanced disease at diagnosis, as they were undergoing pre-surgical neoadjuvant chemotherapy. However, the samples analyzed in the present study accounted for all the tumor patients admitted to the Santa Rita de Cassia Hospital Pathology Service.

In contrast to other Brazilian studies, no statistically significant differences were observed in hormone receptor expression in the analyzed age groups. Studies using samples from Ribeirão Preto (13) demonstrated that $\mathrm{PR}^{+}$tumors were less frequent in women aged $\leq 40$ years compared to women aged $\geq 50$ years ( $36.2 \%$ or 21 cases vs. $58.4 \%$ or 38 cases), while studies using samples from Florianópolis (12) found $38.9 \%$ (35 cases) $\mathrm{ER}^{-} / \mathrm{PR}^{-}$and $24.5 \%$ (22 cases) $\mathrm{ER}^{+} / \mathrm{PR}^{+}$tumors in the age group $\leq 35$ years.

HER2 overexpression in the present study was similar to other studies in the literature, where HER2 was overexpressed in $\sim 15-25 \%$ of the breast cancers (14). When comparing patients aged $\geq 50$ years to those aged $\leq 50$ years, no statistically significant differences were observed in the HER2 expression. Similar results were observed in samples from Ribeirão Preto (13). The luminal immunohistochemical profile observed in our study $(82.1 \%$; 95\% CI, 76.20-88.0\%) was higher compared to results of other studies available in the literature (60-70\%) (15), as well as compared to the Brazilian sample reported by Bacchi et al (15), reporting a luminal profile percentage of $68.21 \%$ (249 cases). By contrast, although consistent with our results, in their study Bacchi et al (15) also observed a trend towards triple-negative profile in the younger age group (27.1\%, 79 cases).

The mean age at diagnosis observed for malignant ovarian tumors in the present study was consistent with that of a Brazilian study using samples from São Paulo (São Paulo) (16) which reported a mean age at diagnosis of 53.5 years, accounting for $58.8 \%$ of the patients $>50$ years of age. The mean age for malignant ovarian tumors was also in concordance with the findings of a study using samples from Jundiaí (São Paulo, Brazil) (17), reporting a mean age of 55 years at diagnosis for malignant ovarian tumors.

In their study, DeLand et al (18) reported a mean age at diagnosis for malignant ovarian tumors (50 years) that was similar to the findings of the present study, although the mean age for benign tumors (34 years) was lower compared to the one we detected.

Breast and ovarian tumors are poorly characterized epidemiologically in several Brazilian regions, thus this study adds considerably to other Brazilian studies, providing detailed information about the Espirito Santo state. Improved knowledge on these tumors may have direct implications on the prevention, diagnosis and treatment strategies in Brazil and other countries.

\section{Acknowledgements}

This study was funded in part by Fibria Celulose. EVW was supported by a FAPES PhD scholarship. CFBG, MLE, LNRA and ES were supported by a CNPq scholarship. 


\section{References}

1. Ashton-Prolla P, Giacomazzi J, Schmidt AV, Roth FL, Palmero EI, Kalakun L, Aguiar ES, Moreira Susana M, Batassini E, Belo-Reyes V, Schuler-Faccini L, Giugliani R, Caleffi $\mathrm{M}$ and Camey SA: Development and validation of a simple questionnaire for the identification of hereditary breast cancer in primary care. BMC Cancer 9: 283-291, 2009.

2. Palmero EI, Ashton-Prolla P, Rocha JCC, Vargas FR Kalakun L, Blom MB, Azevedo SJ, Caleffi M, Giugliani R and Schüler-Faccini L: Clinical characterization and risk profile of individuals seeking genetic counseling for hereditary breast cancer in Brazil. J Genet Couns 16: 363-371, 2007.

3. National Cancer Institute: United States-Latin America Cancer Research Network (US-LA CRN): US-LA CRN Partner: Brazil http://www.cancer.gov/aboutnci/organization/olacpd/crn/brazil. Accessed, 2011

4. Freitas R Jr, Freitas NM, Curado MP, Martins E, Silva CM, Rahal RM and Queiroz GS: Incidence trend for breast cancer among young women in Goiânia, Brazil. Sao Paulo Med J 128: 81-84, 2010.

5. Schuijer M and Berns EM: TP53 and ovarian cancer. Hum Mutat 21: 285-291, 2003

6. Medeiros LR, Rosa DD, da Rosa M and Bozzetti MC: Accuracy of CA 125 in the diagnosis of ovarian tumors: a quantitative systematic review. Eur J Obstet Gynecol Reprod Biol 142: 99-105, 2009.

7. Dansonka-Mieszkowska A, Ludwig AH, Kraszewska E and Kupryjanczyk J: Geographical variations in TP53 mutational spectrum in ovarian carcinomas. Ann Hum Genet 70: 594-604, 2006.

8. Appel M, Mônego H, Ramos JGL, Poli MEH, Stein AT, Silva JM, Bernd FF and Bersh GP: Screening and diagnosis of ovarian cancer. Rev AMRIGS 53: 313-318, 2009 (In Portuguese).

9. World Health Organization: International Agency for Research on Cancer: GLOBOCAN 2008: Summary statistics, Brazil. http://globocan.iarc.fr/factsheets/populations/factsheet.asp?uno= 76\#KEY. Accessed January 9, 2012.
10. Schneider IJ and d'Orsi E: Five-year survival and prognostic factors in women with breast cancer in Santa Catarina state, Brazil. Cad Saude Publica 25: 1285-1296, 2009 (In Portuguese).

11. Guerra MR, Mendonça GA, Bustamante-Teixeira MT, Cintra JR, Carvalho LM and Magalhães LM: Five-year survival and prognostic factors in a cohort of breast cancer patients treated in Juiz de Fora, Minas Gerais State, Brazil. Cad Saude Publica 25: 2455-2466, 2009 (In Portuguese).

12. Crippa CG, Hallal ALC, Dellagiustina AR, Traebert ÉE, Gondin G and Pereira C: Clinical and epidemiological profile of breast cancer in young women. ACM Arq Catarin Med 32: 50-58, 2003 (In Portuguese).

13. Clagnan WS, Andrade JM, Carrara HH, Tiezzi DG, Reis FJ, Marana HR and Abrão RA: Age as an independent factor of prognosis in breast cancer. Rev Bras Ginecol Obstet 30: 67-74, 2008 (In Portuguese).

14. Brito NMB, Sampaio PCM, Castro AAH and Oliveiras MR: Clinical characteristics of women with invasive ductal breast carcinoma undergone neoadjuvant chemotherapy. Rev Para Med 21: 37-41, 2007 (In Portuguese).

15. Bacchi LM, Corpa M, Bacchi CE and Carvalho FM: Pathological and molecular characterization of breast carcinomas of young women. Rev Bras Mastol 19: 42-46, 2009 (In Portuguese).

16. Fernandes LRA, Lippi UG and Baracat FF: Ovarian tumor risk index incorporating age, ultrasound and CA-125. Rev Bras Ginecol Obstet 25: 345-351, 2003 (In Portuguese).

17. Luiz BM, Miranda PF, Maia EMC, Machado RB, Giatti MJL, Filho AA and Borges JBR: Epidemiological study of ovary tumor patients in the city of Jundiaí from June 2001 to June 2006. RBC 55: 247-253, 2009.

18. DeLand M, Fried A, van Nagell JR and Donaldson ES: Ultrasonography in the diagnosis of tumors of the ovary. Surg Gynecol Obstet 148: 346-348, 1979. 